\title{
Fertility traits of Holstein, Brown Swiss, Simmental, and Alpine Grey cows are differently affected by herd productivity and milk yield of individual cows
}

\author{
Hugo Toledo-Alvarado, Alessio Cecchinato, ${ }^{1}$ and Giovanni Bittante \\ Department of Agronomy, Food, Natural Resources, Animals and Environment (DAFNAE), University of Padova, 35020 Legnaro, Italy
}

\begin{abstract}
Milk yield has a strong effect on fertility, but it may vary across different herds and individual cows. Therefore, the aim of this study was to assess the effects of breed and its interaction with level of milk production at the herd level (Herd-L) and at a cow-within-herd level (Cow-L) on fertility traits in dairy cattle. Data were gathered from Holstein $(\mathrm{n}=17,688)$, Brown Swiss ( $\mathrm{n}=32,697)$, Simmental $(\mathrm{n}=27,791)$, and Alpine Grey $(\mathrm{n}=13,689)$ cows in northeastern Italy. The analysis was based on records from the first 3 lactations in the years 2011 to 2014. A mixed model was fitted to establish milk production levels of the various herds (Herd-L) and individual cows (Cow-L) using milk as a response variable. The interval fertility traits were interval from calving to first service, interval from first service to conception, and number of days open. The success traits were nonreturn rate at $56 \mathrm{~d}$ after first service, pregnancy rate at first service, and the number of inseminations. The interval from calving to first service, interval from first service to conception, and number of days open were analyzed using a Cox's proportional hazards model. The nonreturn rate at 56 d after first service, pregnancy rate at first service, and the number of inseminations were analyzed using logistic regression. There was a strong interaction between breed and productivity class at both Herd-L and Cow-L on all traits. The effects of herd and cow productivity differed from each other and differed among breeds. The dual-purpose Simmental and Alpine Grey breeds had better fertility than the specialized Holstein and Brown Swiss dairy cows; this difference is only partly attributable to different milk yields. Greater herd productivity can result in higher fertility in cows, whereas higher milk yield of individual cows within a herd results in lower fertility. These effects at both Herd-L and Cow-L are curvilinear and are stronger in
\end{abstract}

Received December 12, 2016.

Accepted June 6, 2017.

${ }^{1}$ Corresponding author: alessio.cecchinato@unipd.it dual-purpose breeds, which was more evident from low to intermediate milk yield levels than from central to high productivity classes. Disentangling the effects of milk productivity on fertility at Herd-L and Cow-L and taking the nonlinearity of response into account could lead to better modeling of populations within breed. It could also help with management - for example, in precision dairy farming of dairy and dual-purpose cattle. Moreover, assessing the fertility of various breeds and their different responses to herd and individual productivity levels could be useful in devising more profitable crossbreeding programs in different dairy systems.

Key words: fertility, survival analysis, milk production, genotype $\times$ environment

\section{INTRODUCTION}

The reduction in fertility rate along with the increase in milk production in dairy cattle over recent decades (Lucy, 2001) has raised much interest in investigating its causes and in seeking solutions (Walsh et al., 2011; López-Gatius, 2012). Several studies have reported a negative genetic correlation between milk production and fertility traits (Pryce et al., 2004; Tiezzi et al., 2011, 2012), whereas others have found reproductive loss in dairy cattle to be associated with increased herd sizes, higher rates of inbreeding, changes in reproductive physiology, and worsening of body condition (Lucy, 2001; Walsh et al., 2011; Tiezzi et al., 2013). As a consequence, the number of days open has increased, pregnancy rates have decreased, and the level of involuntary culling has increased. However, caution should be exercised in interpreting these negative relationships because the effects on reproductive performance associated with individual cows may be confounded with those at a herd level, which could lead to errors in interpretation. A more comprehensive assessment drawing on expertise from multiple scientific disciplines is needed to study the causes and effects of fertility loss (Bello et al., 2012). The diverse native characteristics of different breeds, and the different genetic improvement schemes among breeds and in different countries, mean that dairy cattle populations around the world have 
different genetic levels of fertility (Nilforooshan et al., 2009).

To address the problem, several countries have incorporated fertility traits into their genetic evaluations, and different models and methodologies have been proposed (VanRaden et al., 2004; Huang et al., 2007). A review by Egger-Danner et al. (2015) found that 15 countries around the world with high levels of milk production include fertility in their total merit indices. It has been suggested that survival analysis may be a better option than linear methods, especially for eventtime censored traits, because it allows partial records to be used in the analysis (Schneider et al., 2005). Phuong et al. (2016) proposed an extended lifetime performance model that incorporates the effect of variations in milk yield, energy balance, and body condition on the reproductive success of individual cows. The model therefore successfully simulates the reproductive performance of different cow genotypes across feeding systems.

Crossbreeding of dairy cattle has been used as an alternative to pure breeding and has led to improvements in various traits, including fertility (Weigel and Barlass, 2003). Different breed combinations have resulted in differences in fertility traits (Weigel and Barlass, 2003; Heins et al., 2006; Malchiodi et al., 2014). This means that a better understanding of the characteristics of individual breeds with respect to these traits is needed to design more profitable crossbreeding programs.

Vargas et al. (1998) studied interval fertility traits using event-time techniques of different breeds and crossbreeds and reported that heifers in herds with lower milk yields were more likely to be bred. They found a significant difference between the effects of the milk yield of primiparous cows on interval (d) between calving and first recorded insemination (iCF) and on number of days open (DO). They also reported a significant effect of heifer weight on age at first calving: herds and heifers with heavier BW at $390 \mathrm{~d}$ had a higher probability of calving. Bello et al. (2012) point out that the associations between productivity and fertility may have been overlooked in the past because of confounding factors and inappropriate statistical analyses, the results of which may have been misinterpreted. According to these authors, lack of a clear distinction between herd level (Herd-L) and cow-within-herd level (Cow-L) in the modeling and between the effects of different dairy production systems may also contribute to misleading conclusions being drawn. LeBlanc (2010) investigated the association between milk production rate and reproductive performance at both Herd-L and Cow-L using pregnancy, insemination, and calving rates as indicators of fertility and found a positive association between pregnancy rate and earlier first insemination in high-yielding herds and cows. The author reported that a high milk yield in cattle may be compatible with good reproductive performance and remarked on the complexity of fertility and the danger of assessing it with only one indicator (i.e., pregnancy rate). In this article, we assess the effect of breed of cow and the interaction of breed and milk productivity measured at Herd-L and Cow-L on interval fertility traits, fertility success traits, and number of inseminations (INS) per cow in various breeds of dairy cattle (Holstein, Brown Swiss, Simmental, and Alpine Grey).

\section{MATERIALS AND METHODS}

\section{Field Data}

Female fertility and milk production data were collected by the Breeders Federation of Alto Adige/ Südtirol (Associazione Provinciale delle Organizzazioni Zootecniche Altoatesine/Vereinigung der Südtiroler Tierzuchtverbände, Bolzano/Bozen, Italy) from the northeast of Bolzano (Bozen province) in Italy. The region is mountainous, and its farms are mainly small and operate various systems, from the very traditional (small to medium herd sizes, old buildings, tied animals, lactating cows moved to mountain pastures during the summer) to the more modern (large herd sizes, recent buildings with milking parlors and free animals, high levels of milk production, TMR feeding system; Sturaro et al., 2013). The test days cover the period from 2011 to 2015. Only records from the first 3 lactations and calvings of each cow from the years 2011 to 2014 were analyzed to exclude cows with fertility events in progress. Lactation period was divided into 11 categories of DIM; each category comprised $30 \mathrm{~d}$ except the last, an open category of $>300$ DIM. Breeds with few data and crossbred animals were excluded from the analysis.

\section{Trait Definition and Data Editing}

The interval fertility traits were defined as $\mathrm{iCF}$, the interval between first service and conception (iFC), and DO. The success traits analyzed were the nonreturn rate at $56 \mathrm{~d}$ after first service (NRR) and pregnancy rate at first service (PRF). The NRR and PRF were coded as binary variables $(0,1)$, where 1 indicated a cow that did not have a second insemination registered within $56 \mathrm{~d}$ of the first service (for NRR) or a cow that became pregnant at the first service (for PRF). The INS was considered an ordinal variable with 5 levels, the fifth being an open class of 5 or more inseminations. Pregnancy status was positively confirmed by a subsequent calving; otherwise, it was set to unknown. Cows without a subsequent calving after the last service were penalized by the addition of a penalty insemination. 
Gestation length was required to be within $30 \mathrm{~d}$ of the average for each breed (about $\pm 5 \%$ within the average gestation length for all the breeds average), and if the pregnancy was outside this limit the record was excluded. Calving interval, $\mathrm{iCF}, \mathrm{iFC}$, and DO were required to be lower than the average $+3 \mathrm{SD}(733,243$, 476 , and 403 d, respectively). Data above the upper limits were replaced with the upper limit value, and the record was considered censored. The lower limit for $\mathrm{iCF}$ and $\mathrm{iFC}$ was $0 \mathrm{~d}$, whereas for DO it was $20 \mathrm{~d}$. If there was no confirmation of pregnancy, the record was considered censored. After editing, approximately $12 \%$ of the original data were eliminated, and the final data set comprised 11,442 Holstein, 21,043 Brown Swiss, 16,727 Simmental, and 8,237 Alpine Grey cows distributed across 4,013 herds, many of which ( $47 \%$ of the total) were multibreed herds.

\section{Statistical Analysis}

There were large variations in the size, breed composition, and level of infrastructure of the herds. To establish the milk production levels of the different herds (Herd-L) and the individual cows within the herds (Cow-L), a mixed model was fitted using the MIXED procedure in SAS/STAT (SAS Institute, 2012) and with restricted maximum likelihood as the estimation method. The mixed model for Herd-L was

$$
\begin{aligned}
& y_{i j k l m n o p}=\mu+D_{i}+C_{j}+b_{1} H_{k}+b_{2} B_{l} \\
& +b_{3} S_{m}+b_{4} G_{n}+R_{o}+e_{i j k l m n o p}
\end{aligned}
$$

where $y_{i j k l m n o p}$ is the milk production for the test day; $\mu$ is the general mean; $D_{i}$ is the category of DIM $(i=11$ categories); $C_{j}$ is the year of the test day $(j=2011-$ 2015); $H_{k}, B_{l}, S_{m}$, and $G_{n}$ are the percentages of Holstein, Brown Swiss, Simmental, and Alpine Grey cows in the herd, respectively; $b_{1}, b_{2}, b_{3}$, and $b_{4}$ are the linear regression coefficients for $H_{k}, B_{l}, S_{m}$, and $G_{n}$, respectively; $R_{o}$ is the random effect of herd $(o=4,013$ herds); and $e_{i j k l m n o p}$ is the random experiment error. Herd and residuals were assumed to have a normal distribution with a mean of zero and variances of $\sigma_{h}^{2}$ and $\sigma_{e}^{2}$, respectively. The herds' solutions were used to classify them into 5 milk productivity levels (1-5).

The mixed model for Cow-L for each breed was

$$
y_{i j k l m n}=\mu+D_{i}+C_{j}+H_{k}+L_{l}+A_{m}+e_{i j k l m n},
$$

where $y_{i j k l m n}$ is the milk production for the test day, $\mu$ is the general mean, $D_{i}$ is the category of DIM $(i=11$ categories $), C_{j}$ is the year of the test day $(j=2011-$ 2015), $H_{k}$ is the Herd-L ( $k=5$ herd levels), $L_{l}$ is the number of the lactation $(l=1-3), A_{m}$ is the random effect of the animal ( $m=57,449$ cows), and $e_{i j k l m n}$ is the random experiment error. Animal and residuals were assumed to have a normal distribution with a mean of zero and variances of $\sigma_{a}^{2}$ and $\sigma_{e}^{2}$, respectively. The cows' solutions were used to classify them into 5 milk productivity levels (A-E). The central classes (Herd-L 3, CowL C), which represent the majority of the herds (Herd$\mathrm{L} 3: \mathrm{n}=1,576 ; 39.3 \%$ of all herds) and cows (Cow-L C: $\mathrm{n}=23,132 ; 40.4 \%$ of all cows), were used as reference values in the subsequent analysis of fertility traits.

\section{Analysis of Fertility Traits}

The analysis was carried out using the PHREG procedure in SAS/STAT (SAS Institute, 2012) with a proportional hazard model (Cox, 1972) fitted for interval fertility traits (iCF, iFC, and DO). The model was

$$
\lambda_{i}\left(t \mid X_{i}\right)=\lambda_{0}(t) e^{\left(\mathbf{x}_{i}^{\prime} \boldsymbol{\beta}\right)},
$$

where $\lambda_{i}\left(t \mid X_{i}\right)$ is the hazard (hazard ratio; HR) of receiving the first service after calving at time $t$ for $\mathrm{iCF}$, becoming pregnant after the first insemination at time $t$ for iFC, or becoming pregnant after calving at time $t$ for DO; $\lambda_{0}(t)$ is the baseline hazard function; $\boldsymbol{\beta}$ is an unknown vector of regression coefficients for the fixed effects; and $\mathbf{x}^{\prime}$ is a vector for the fixed effects of the number of the lactation (1-3), the year of calving (2011-2014), and breed interacting with either herd (20 levels) or cow within herd (20 levels). The hazard or risk in this context does not have a negative meaning. In fact, it refers to the probability of the occurrence of the reproductive event.

The variables NRR and PRF were analyzed by logistic regression using the LOGISTIC procedure in SAS/ STAT (SAS Institute, 2012) and with a binary logit model with the form

$$
\operatorname{logit}(\pi)=\log \left(\frac{\pi}{1-\pi}\right)-\alpha+\boldsymbol{\beta}^{\prime} \mathbf{x},
$$

where $\pi=\operatorname{Pr}(Y=1 \mid x)$, which is the response probability (odds ratio; $\mathbf{O R}$ ) of becoming pregnant for NRR and PRF; $\alpha$ is the intercept of the parameter; $\boldsymbol{\beta}=\left(\boldsymbol{\beta}_{1}\right.$, $\left.\ldots, \boldsymbol{\beta}_{i}\right)$ is the vector of $i$ slope parameters; and $\mathbf{x}$ is a vector for the fixed effects of the number of the lactation (1-3), the year of calving (2011-2014) and breed interacting with either herd (20 levels) or cow within herd (20 levels). 
The variable INS was analyzed by logistic regression using the LOGISTIC procedure in SAS/STAT (SAS Institute, 2012) and with a cumulative logit model, a parallel lines regression model based on cumulative probabilities, with the form

$$
g[\operatorname{Pr}(Y \leq i \mid x)]=\alpha_{i}+\boldsymbol{\beta}^{\prime} \mathbf{x}, i=1,2,3,4,5,
$$

where $g[\operatorname{Pr}(Y \leq i \mid x)]$ is the probability (OR) of requiring fewer inseminations to become pregnant; $\alpha_{1}, \ldots, \alpha_{5}$ are the intercept parameters for the first 5 inseminations after calving; $\boldsymbol{\beta}=\left(\boldsymbol{\beta}_{1}, \ldots, \boldsymbol{\beta}_{i}\right)$ is the vector of the $i$ slope parameters; and $\mathbf{x}$ is the vector for the fixed effects of the number of the lactation (1-3), the year of calving (2011-2014), and breed interacting with either herd (20 levels) or cow within herd (20 levels).

The HR and OR estimates together with their confidence intervals for each breed were used to plot these across the different Herd-L or Cow-L. Linear and quadratic contrasts for each breed across Herd-L and Cow$\mathrm{L}$ were then estimated. A significant $(P<0.05)$ higher order contrast was used to plot a linear or quadratic tendency.

\section{RESULTS AND DISCUSSION}

\section{Herd-L and Cow-L According to Milk Production}

Solution values were used to classify herds and individual cows into 5 categories: Herd-L 1 to 5 or Cow-L A to E. Figure 1 shows the frequencies of the herd and cow-within-herd categories obtained from the mixedmodel analysis. The distribution of the observations of herds and cows across the 5 classes $(<-1.5 \sigma,-1.5 \sigma$ to $-0.5 \sigma,-0.5 \sigma$ to $+0.5 \sigma,+0.5 \sigma$ to $+1.5 \sigma$, and $>+1.5 \sigma)$ was centered to $0 \pm$ standard deviation of daily milk production.

The average milk production levels of each breed within each Herd-L and Cow-L class are presented in Figure 2. Holsteins had the highest average daily milk production in each Herd-L class $(21.9,24.0,26.7,28.9$, and $31.6 \mathrm{~kg} / \mathrm{d}$ in Herd-L 1, 2, 3, 4, and 5, respectively) followed by herds comprising dual-purpose Simmental and Brown Swiss cows, which produced about 4 $\mathrm{kg} / \mathrm{d}$ less milk per cow in each of the 5 Herd-L classes. The average milk production of herds of local dualpurpose Alpine Greys was about $10 \mathrm{~kg} / \mathrm{d}$ lower than the Holsteins in each Herd-L class. These differences are consistent with the different genetic backgrounds for milk yield of the 4 breeds and with the different herd characteristics in terms of geographical area, size, facilities, management, feeding, health, and so on. Holsteins are often reared on modern dairy farms using loose housing, milking parlors, and TMR; local breeds a)

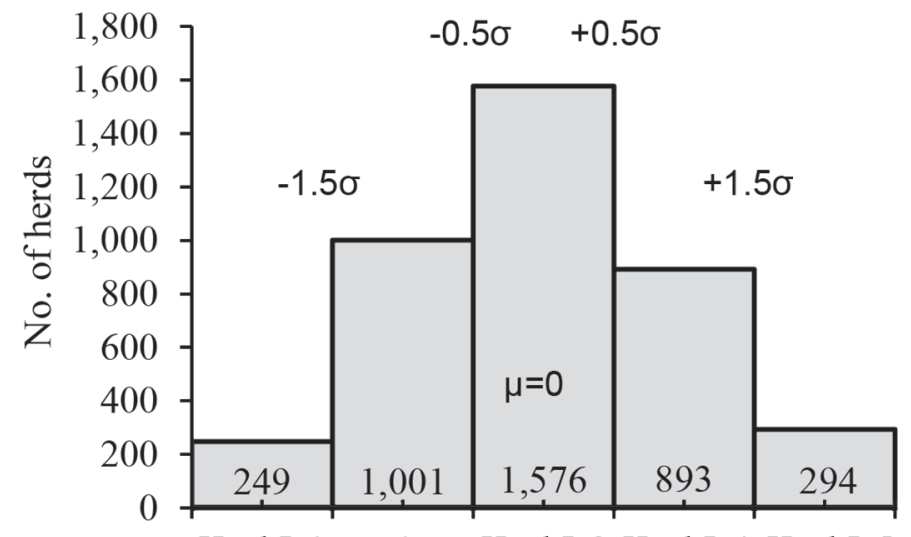

Herd-L 1 Herd-L 2 Herd-L 3 Herd-L 4 Herd-L 5

b)

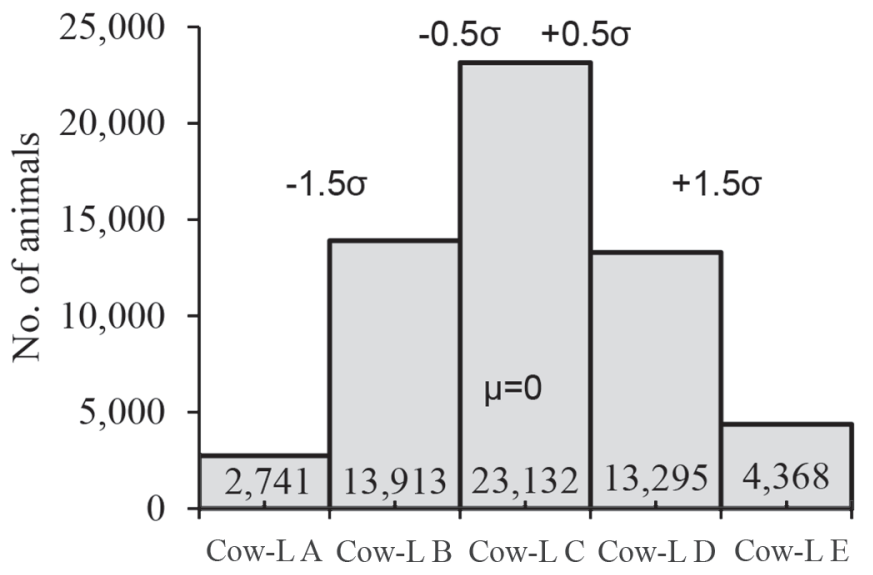

Figure 1. Number of herds in each herd level (Herd-L; 1-5) and number of cows in each cow-within-herd level (Cow-L; A-E) according to their solutions for milk production.

are often kept on very traditional farms (e.g., tied cows, hay feed with some concentrates); and Brown Swiss and Simmental cows may be kept in both types of dairy systems (Sturaro et al., 2013). Recent research carried out in the same area on multibreed herds (Stocco et al., 2017) found lower within-herd differences in milk productivity: Holsteins produced about $3 \mathrm{~kg} / \mathrm{d}$ more than the Brown Swiss and Simmental cows and $7 \mathrm{~kg} / \mathrm{d}$ more than the Alpine Greys.

Average milk yield values of the Cow-L classes were slightly greater than those of the corresponding Herd$\mathrm{L}$ classes because there were more cows in the more productive Herd-L classes than in the less productive classes. As a consequence, the average milk yields of the cows of the 4 breeds studied were greater than the 


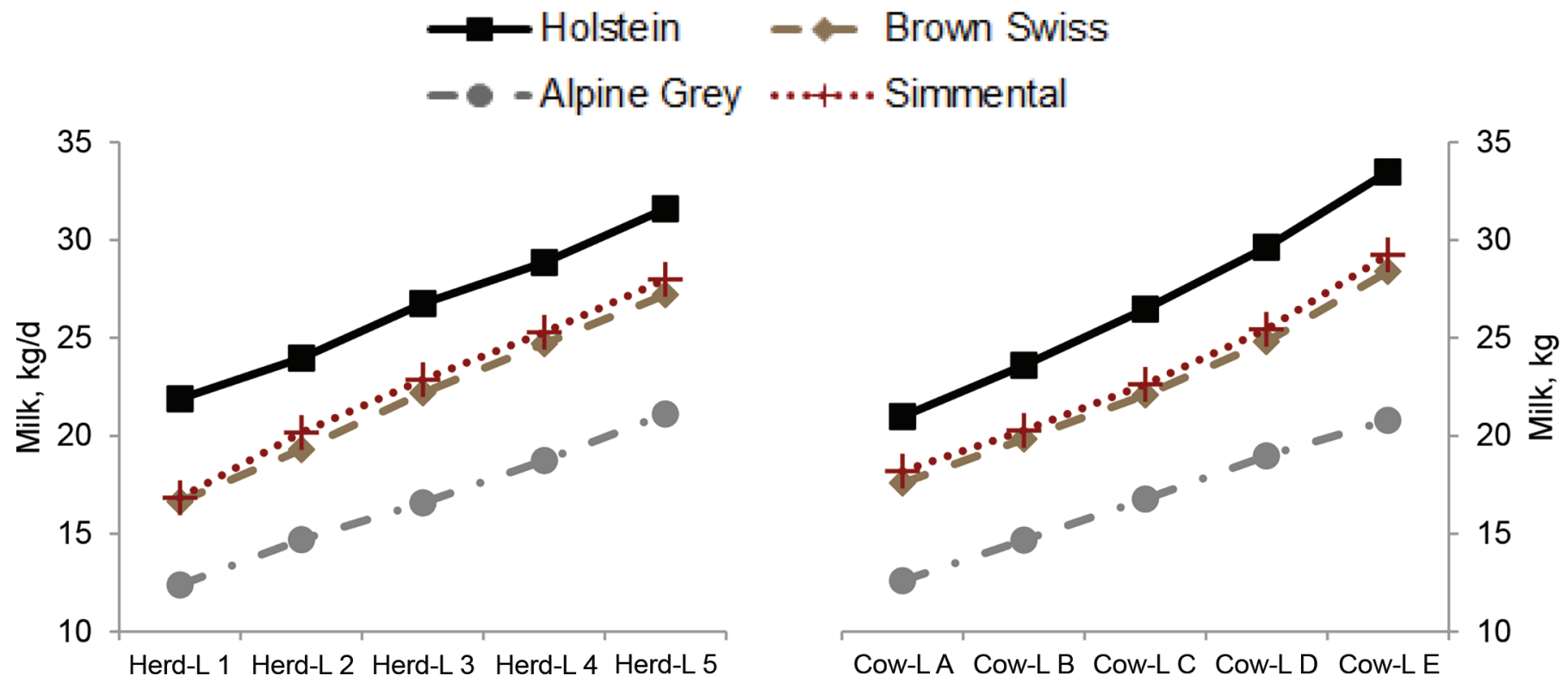

Figure 2. Means for the milk yield of cows of the 4 breeds at the herd level (Herd-L; 1-5) and cow-within-herd level (Cow-L; A-E). Color version available online.

average milk yields of herds of the same breed. The standard deviation of the Cow-L was similar to that of the Herd-L of the same breed, but the pattern of Cow-L averages was slightly curvilinear because the distribution of individual cows is slightly skewed due to the different numbers of cows in the 2 extreme classes (Figure 1). The classification shows that milk production of the lowest category of Holstein-Herd-L 1 (21.9 $\mathrm{kg} / \mathrm{d})$ or Cow-L A $(21.1 \mathrm{~kg} / \mathrm{d})$ - was similar to that of the highest categories of Alpine Grey $(21.1 \mathrm{~kg} / \mathrm{d}$ for Herd-L 5; $20.8 \mathrm{~kg} / \mathrm{d}$ for Cow-L 5 ), whereas the categories of the Brown Swiss and Simmental herds and cows partly overlap with both the Holstein and Alpine Grey categories.

\section{Descriptive Statistics}

The descriptive statistics for $\mathrm{iCF}, \mathrm{iFC}$, and DO are reported in Table 1. On average, cows with uncensored records were inseminated $84.7 \mathrm{~d}$ after calving across all breeds, conception was reported to be successful 31.5 $\mathrm{d}$ later, and the interval between calving and conception was $117.1 \mathrm{~d}$. The largest number of records was obtained for the Brown Swiss breed $(32,697)$ and the

Table 1. Descriptive statistics for interval from calving to first service (iCF), interval from first service to conception (iFC), and days open (DO)

\begin{tabular}{|c|c|c|c|c|c|c|}
\hline \multirow[b]{2}{*}{ Trait } & \multirow[b]{2}{*}{$\mathrm{n}$} & \multirow[b]{2}{*}{ Censored, \% } & \multicolumn{2}{|c|}{ Uncensored records, d } & \multicolumn{2}{|c|}{ Censored records, $\mathrm{d}$} \\
\hline & & & Mean & $\mathrm{SD}$ & Mean & $\mathrm{SD}$ \\
\hline \multicolumn{7}{|l|}{$\mathrm{iCF}$} \\
\hline Holstein & 17,688 & 29.9 & 93.7 & 40.8 & 114.7 & 58.2 \\
\hline Brown Swiss & 32,697 & 29.1 & 87.3 & 37.7 & 107.0 & 55.8 \\
\hline Simmental & 27,791 & 23.4 & 77.5 & 32.3 & 92.4 & 46.8 \\
\hline Alpine Grey & 13,689 & 22.3 & 80.6 & 31.7 & 92.8 & 46.9 \\
\hline \multicolumn{7}{|l|}{ iFC } \\
\hline Holstein & 17,688 & 28.6 & 40.4 & 63.7 & 81.0 & 100.3 \\
\hline Brown Swiss & 32,697 & 28.3 & 38.3 & 62.6 & 79.4 & 102.0 \\
\hline Simmental & 27,791 & 23.1 & 25.0 & 47.7 & 52.7 & 78.4 \\
\hline Alpine Grey & 13,689 & 22.0 & 22.5 & 46.2 & 48.9 & 77.2 \\
\hline \multicolumn{7}{|l|}{ DO } \\
\hline Holstein & 17,688 & 29.2 & 135.5 & 72.8 & 193.8 & 103.7 \\
\hline Brown Swiss & 32,697 & 28.6 & 126.6 & 71.5 & 183.6 & 103.6 \\
\hline Simmental & 27,791 & 23.2 & 102.9 & 57.3 & 145.2 & 87.6 \\
\hline Alpine Grey & 13,689 & 22.1 & 103.5 & 55.3 & 141.7 & 96.9 \\
\hline
\end{tabular}


lowest for the Alpine Grey breed (13,689). The distribution of records across levels of production (Herd-L, Cow-L) was similar for all breeds.

The percentages of censored records ranged from $22 \%$ for the dual-purpose breeds to $29 \%$ for the specialized dairy breeds. These proportions of censored data suggest that the different breeds have different culling rates and highlight the importance of including these data in the analysis to decrease bias. The high proportions of censored data in our study justified the use of survival analysis to study time-dependent traits. Vargas et al. (1998) reported a rate of $10 \%$ censored records for DO in primiparous Holstein and Jersey cows in Costa Rica, whereas Malchiodi et al. (2014) reported rates of 7.5, 24.8 , and $18.7 \%$ for $\mathrm{iCF}, \mathrm{DO}$, and $\mathrm{iFC}$, respectively, in Holstein cows in Italy. In addition, Tiezzi et al. (2011) reported $16.9 \%$ censored records for $\mathrm{DO}$ and $\mathrm{iFC}$ in a previous study with Brown Swiss cows in the same region of northeast Italy.

The estimated means for Holstein cows were the highest values across breeds for these traits. Brown Swiss cows exhibited slightly lower (i.e., more favorable) values, whereas values of the dual-purpose Simmental and Alpine Grey cows were the lowest. The values for censored records were much higher than those for uncensored data - on average $+20,+109$, and $+41 \%$ for $\mathrm{iCF}, \mathrm{iFC}$, and DO, respectively.

The number of records and the percentages of success events for NRR and PRF are shown in Table 2; here, too, the better results were from the dual-purpose breeds. The difference between the 2 extremes (Holstein and Alpine Grey) was about $9 \%$ for NRR but increased to $27 \%$ after confirmation with calving (PRF), a figure that also reflects the higher culling rate of specialized dairy breeds. Similar values (0.71 for NRR and 0.45 for PRF) were obtained for Brown Swiss cows in the same Italian mountain region (Tiezzi et al., 2011), whereas Holstein cows reared on intensive dairy farms on the plains had much lower success rates $(0.40$ for NRR and 0.34 for PRF; Malchiodi et al., 2014) than in the present study. It should be noted that only primiparous cows were included in those studies, whereas our estimates included cows in their first 3 parities. Norman et al. (2009) reported ranges of 45 to $48 \%$ for NRR70 and 24 to $34 \%$ for PRF in Holstein cows compared with ranges of 51 to $54 \%$ for NRR70 and 33 to $41 \%$ for PRF in Jersey cows with several parities in the United States. Variations in milk production levels, nutrition, management, genetics, and herd size may explain the different rates in the various studies.

Descriptive statistics for INS are reported in Table 3. Again, the specialized dairy breeds required the highest INS to get pregnant and the dual-purpose cows required the lowest, with a difference of $22 \%$ between the
Table 2. Number of records and percentages of success events for nonreturn rate at $56 \mathrm{~d}(\mathrm{NRR})$ and pregnancy rate at first service $(\mathrm{PRF})$

\begin{tabular}{lcc}
\hline Trait & $\mathrm{n}$ & $\%$ \\
\hline NRR & & \\
Holstein & 17,688 & 65 \\
Brown Swiss & 32,697 & 66 \\
Simmental & 27,791 & 70 \\
Alpine Grey & 13,689 & 71 \\
PRF & & \\
Holstein & 17,688 & 48 \\
Brown Swiss & 32,697 & 49 \\
Simmental & 27,791 & 58 \\
Alpine Grey & 13,689 & 61 \\
\hline
\end{tabular}

2 extremes (Holstein and Alpine Grey). Comparable results for INS were reported for Holstein primiparous cows reared on the plains, with 2.53 inseminations (Malchiodi et al., 2014), whereas a value of 1.74 inseminations was reported for Brown Swiss cows in the mountains (Tiezzi et al., 2011).

\section{Kaplan-Meier Survival Functions}

Kaplan-Meier estimates of the survival function for $\mathrm{iCF}, \mathrm{iFC}$, and DO are presented in Figure 3a, b, and c, respectively. Figure 3 clearly shows the differences between the specialized dairy (Holstein and Brown Swiss) and dual-purpose (Simmental and Alpine Grey) breeds for all the interval fertility traits examined. With respect to $\mathrm{iCF}$, at $100 \mathrm{~d}$ from calving only $59 \%$ of the Holstein and $62 \%$ of the Brown Swiss cows were inseminated compared with $73 \%$ of Alpine Greys and $75 \%$ of Simmentals. This could indicate a shorter puerperium, earlier heat detection, or a shorter voluntary waiting period for dual-purpose breeds than for specialized dairy breeds (Pryce et al., 2004; Malchiodi et al., 2014).

The Holstein and Brown Swiss also differed from the Simmental and Alpine Grey in iFC. The risk of becoming pregnant $21 \mathrm{~d}$ after first insemination was $41 \%$ for Holstein cows and $42 \%$ for Brown Swiss versus $51 \%$ for Simmentals and 53\% for Alpine Greys. There is an increment in risk approximately every $21 \mathrm{~d}$, corresponding to the natural estrous cycles.

Regarding DO, at $116 \mathrm{~d}$ after calving the Holstein cows had a $44 \%$ risk of becoming pregnant and the

Table 3. Descriptive statistics for number of inseminations to conception (INS)

\begin{tabular}{lccc}
\hline INS & $\mathrm{n}$ & Mean & SD \\
\hline Holstein & 17,688 & 2.23 & 1.30 \\
Brown Swiss & 32,697 & 2.19 & 1.28 \\
Simmental & 27,791 & 1.89 & 1.10 \\
Alpine Grey & 13,689 & 1.83 & 1.07 \\
\hline
\end{tabular}



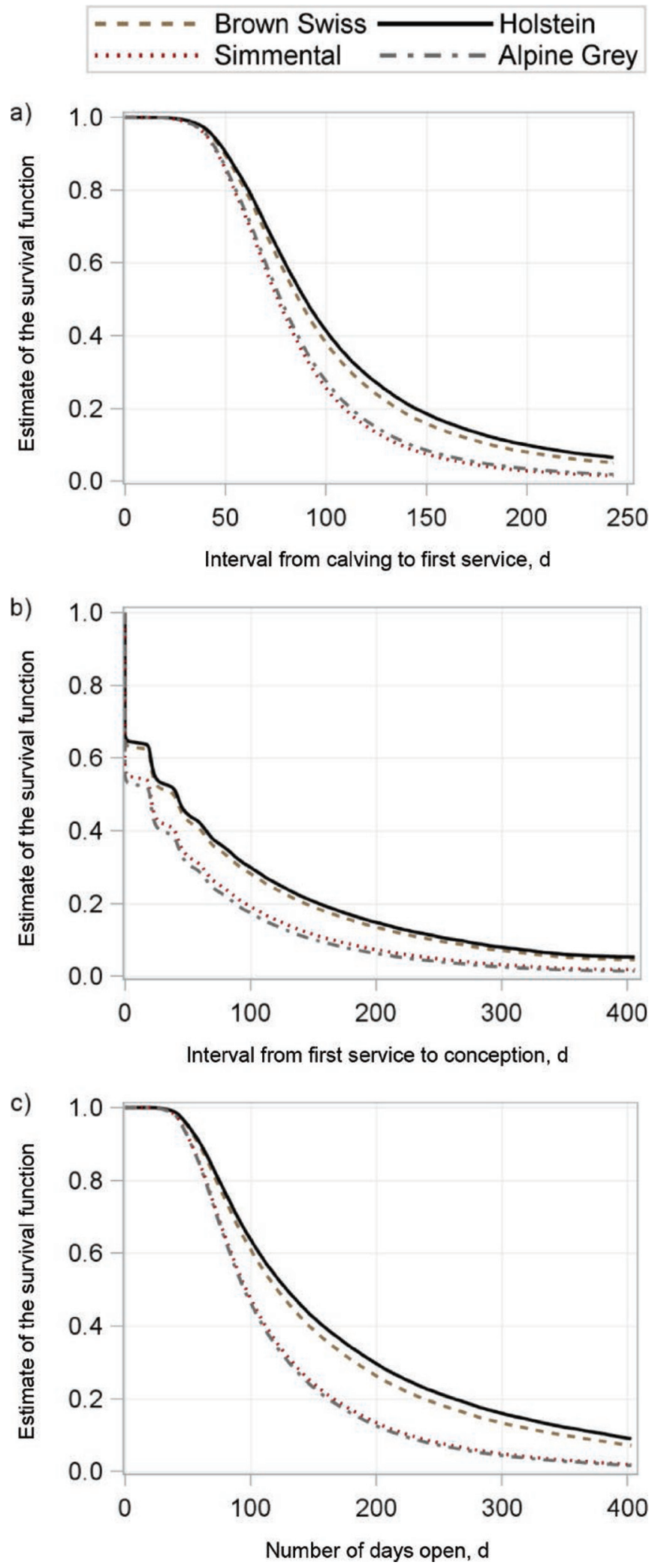

Figure 3. Kaplan-Meier estimates of the survival function for (a) interval from calving to first service, (b) interval from first service to conception, and (c) number of days open. Color version available online.
Brown Swiss cows had a $48 \%$ risk compared with $63 \%$ for Simmental and $64 \%$ for Alpine Grey cows. Malchiodi et al. (2014) reported Kaplan-Meier curves showing Holsteins as having a $49 \%$ risk of becoming pregnant at $100 \mathrm{~d}$, similar to our results for the same period. Vargas et al. (1998) observed a difference in the survival curves for DO after $100 \mathrm{~d}$ between Holstein and Jersey primiparous cows with different milk yields; cows with the lowest milk yields had the lowest risk.

Because the differences among the 4 breeds examined in the present study due to milk productivity level or environmental conditions cannot be ascertained from Kaplan-Meier curves, these factors will be analyzed in greater detail later. It is worth noting that although Brown Swiss and Simmental cows have very similar milk production levels, their reproductive performances differ; the Brown Swiss are more similar to Holsteins (despite the latter having greater milk production), and Simmentals are more similar to Alpine Greys (despite the latter having lower milk production).

\section{$H R$ for iCF, iFC, and DO}

As we observed an interaction between breed and class of productivity for all traits (at both Herd-L and Cow-L), HR and their confidence intervals for the interval traits (iFC, iCF, and DO) of each breed and productivity class at Herd-L and Cow-L were estimated and are presented in Figure 4. The HR are plotted against the average daily milk yield of the corresponding breed at Herd-L and Cow-L. This representation allows us to compare breeds while simultaneously taking into account their different levels of production. In each figure, the reference value $(\mathrm{HR}=1.00)$ is the central class of milk productivity of Holsteins at Herd-L 3 and Cow-L C.

A first result to note is that the different breeds have different HR estimates for all the interval fertility traits studied, with a few exceptions. Moreover, the various productivity classes (both Herd-L and Cow-L) affect the interval reproduction traits, and this effect differs according to breed (effect of the breed-productivity interaction).

Looking first at the $\mathrm{iCF}$ of Holsteins, we observed that both Herd-L and Cow-L moderately affected the interval between calving and first insemination almost linearly but with opposite signs. In fact, an increase in herd productivity had a favorable effect on this reproductive trait (i.e., it increased the risk of a given calving-insemination interval), whereas an increase in the milk yield of an individual cow negatively affected its reproduction rate. A negative energy balance at the beginning of lactation, which is directly related to a high nutrient demand to produce milk, conflicts with 

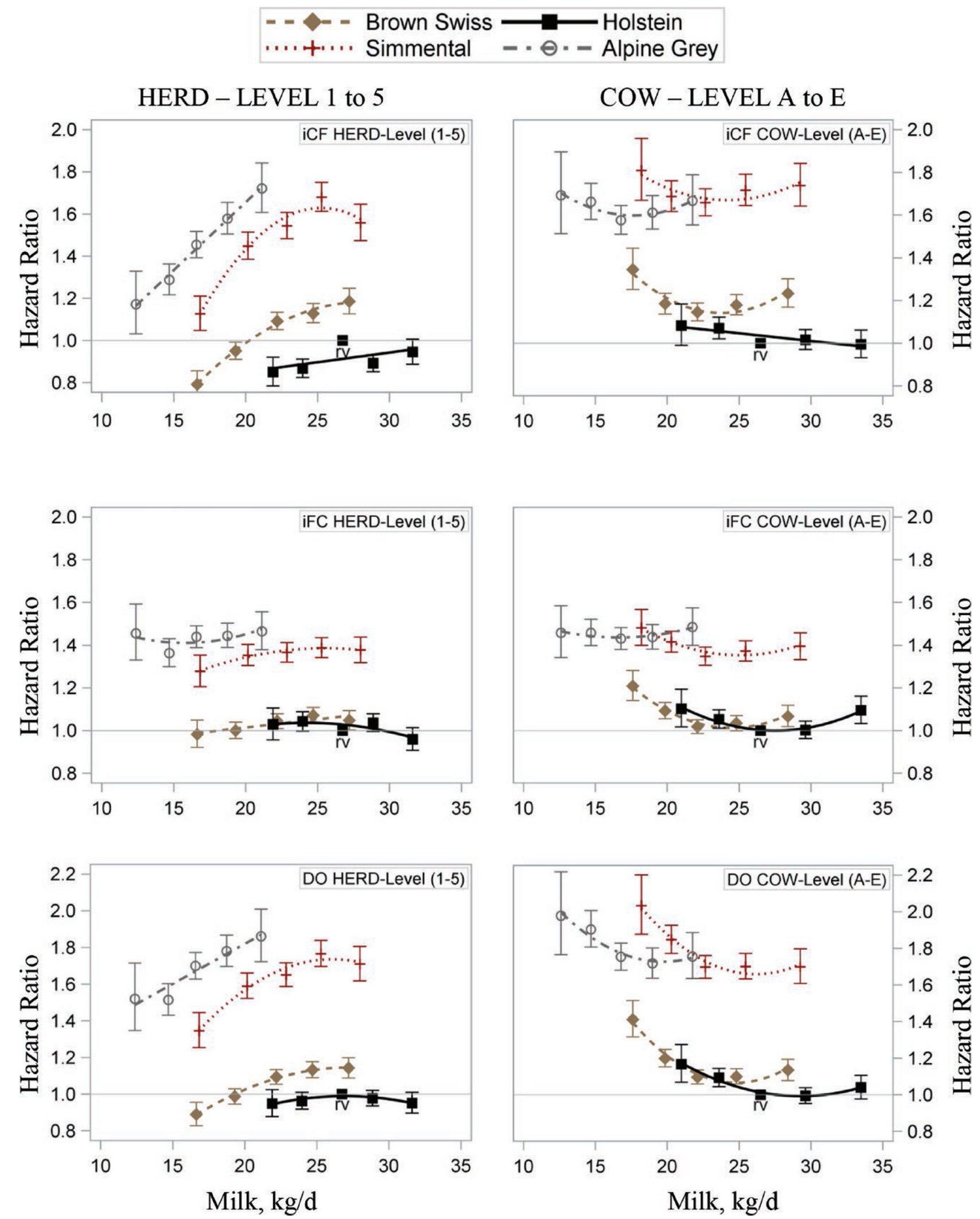

Figure 4. Hazards ratio estimates and their confidence intervals at different levels of milk production for the interval from calving to first service (iCF), interval from first service to conception (iFC), and number of days open (DO) at the herd level and cow-within-herd level. $\mathrm{rv}=$ reference value. Color version available online. 
the expression of estrous behavior and is more evident in cows with a higher milk yield (Harrison et al., 1990).

With regards to Brown Swiss, which is a specialized dairy breed, we found that on average the HR at both Herd-L and Cow-L were greater than the corresponding values for the Holstein breed. Comparing the central classes, at Herd-L 3 and Cow-L C the Brown Swiss were respectively 1.09 and 1.15 times more likely to be inseminated at a given time from calving. The effects of productivity class were also slightly different in the 2 breeds. With respect to Herd-L, we found the favorable effect of productivity in Brown Swiss herds to be more than double that of the Holstein herds. It can also be noted that the pattern was curvilinear as there was a large improvement in the trait moving from the lowest to the central Herd-L and a smaller improvement moving from the central to the highest Herd-L. With respect to Cow-L, the effect of increasing the productivity of Brown Swiss cows was also curvilinear but with the opposite sign. Like the Holsteins, the trait worsened moving from low- to mid-producing cows, whereas a much smaller change (improvement) occurred moving from mid- to high-producing cows. We are unaware of any scientific literature regarding the effects of herd and individual productivity on the fertility traits of Brown Swiss cows.

On average, both dual-purpose breeds had a much higher risk of being inseminated at a given time from calving (i.e., of having a shorter calving-first insemination interval). Comparison of the central classes shows that compared with Holsteins, the Simmentals and Alpine Greys were 1.54 and 1.45 times more likely, respectively, to be inseminated at a given time from calving at Herd-L and 1.66 and 1.58 times, respectively, at Cow-L. Both breeds exhibited a large effect of Herd-L and a moderate effect of Cow-L. The higher the Herd-L the shorter the iCF, with the exception of the highest Herd-L of the Simmental herds (quadratic response). At Cow-L, both breeds exhibited a slightly curvilinear pattern, although it should be noted that the confidence intervals of the HR estimates in these cases were rather high.

For the iFC, we noted a small curvilinear effect of milk productivity at both Herd-L and Cow-L, although with opposite signs (Alpine Greys excluded). Moreover, the 2 dual-purpose breeds had a greater risk of being pregnant at a given interval from first insemination than the specialized dairy breeds at every production level. The 2 dairy breeds overlapped, as did the 2 dualpurpose breeds.

The DO is the sum of iCF and iFC, and here the dual-purpose breeds had even greater average HR values than the specialized breeds at every production level.
The pattern of productivity effects at both Herd-L and Cow-L is influenced more by iCF than by iFC traits. Overall, the Holstein Herd-L had a minor effect on the DO HR, whereas Cow-L tended to have a negative effect going from the lowest Cow-L A $(\mathrm{HR}=1.16)$ to the central Cow-L C (reference value; $\mathrm{HR}=1.00$ ), although this negative effect was not evident at the highest Cow$\mathrm{L} \mathrm{E}(\mathrm{HR}=1.04)$. The pattern of productivity effects on the DO of Brown Swiss cows was similar to that of Holsteins but more accentuated, whereas the average HR values were slightly higher. The Herd-L HR values of the Brown Swiss ranged from 0.89 (Herd-L 1) to 1.14 (Herd-L 5), whereas the Cow-L values ranged from 1.41 (Cow-L A) to 1.14 (Cow-L E). We found a much greater effect of milk productivity on the dual-purpose breeds. The effect was positive at Herd-L (1.52-1.86 for Alpine Grey and 1.36-1.70 for Simmental) and negative at Cow-L (1.98-1.76 for Alpine Grey and 2.03-1.70 for Simmental), especially moving from the low to mid production levels. Vargas et al. (1998) reported differences between Jersey and Brown Swiss crosses for DO, with HR of 1.52 and 1.42, respectively, compared with Holsteins. They also described a nonlinear effect of milk yield on DO, with HR from 0.78 (low milk yield) to 0.92 (high milk yield) compared with intermediate milk yield $(\mathrm{HR}=1.00)$.

\section{OR for PRF, NRR, and INS}

The OR estimates and their confidence intervals for success traits (NRR, PRF, and INS) at Herd-L and Cow-L for the various breeds are presented in Figure 5. Unlike the reproductive interval traits, there was a much greater overlap among the different breeds with respect to NRR at $56 \mathrm{~d}$ after first insemination at both Herd-L and Cow-L. The differences among the average OR of the breeds seem, therefore, to depend more on differences in the average milk yield than on differences in fertility at the same milk production level. The second general observation, common to all 3 success traits, is that the sign of the effect of productivity on fertility is roughly the same at both Herd-L and Cow-L (except with Holsteins). There appears to be a clear negative effect of increased production on NRR at both Herd-L and Cow-L up to a milk yield of about $25 \mathrm{~kg} / \mathrm{d}$, whereas thereafter the effect is not so clear. This explains why productivity effects tend to be significant in dual-purpose breeds but not in dairy breeds. In interpreting these results, it must be taken into account that the first insemination occurs on average at a shorter $\mathrm{iCF}$ in dual-purpose breeds than in dairy breeds. Our results are not consistent with the study carried out by LeBlanc (2010), who found a positive association 

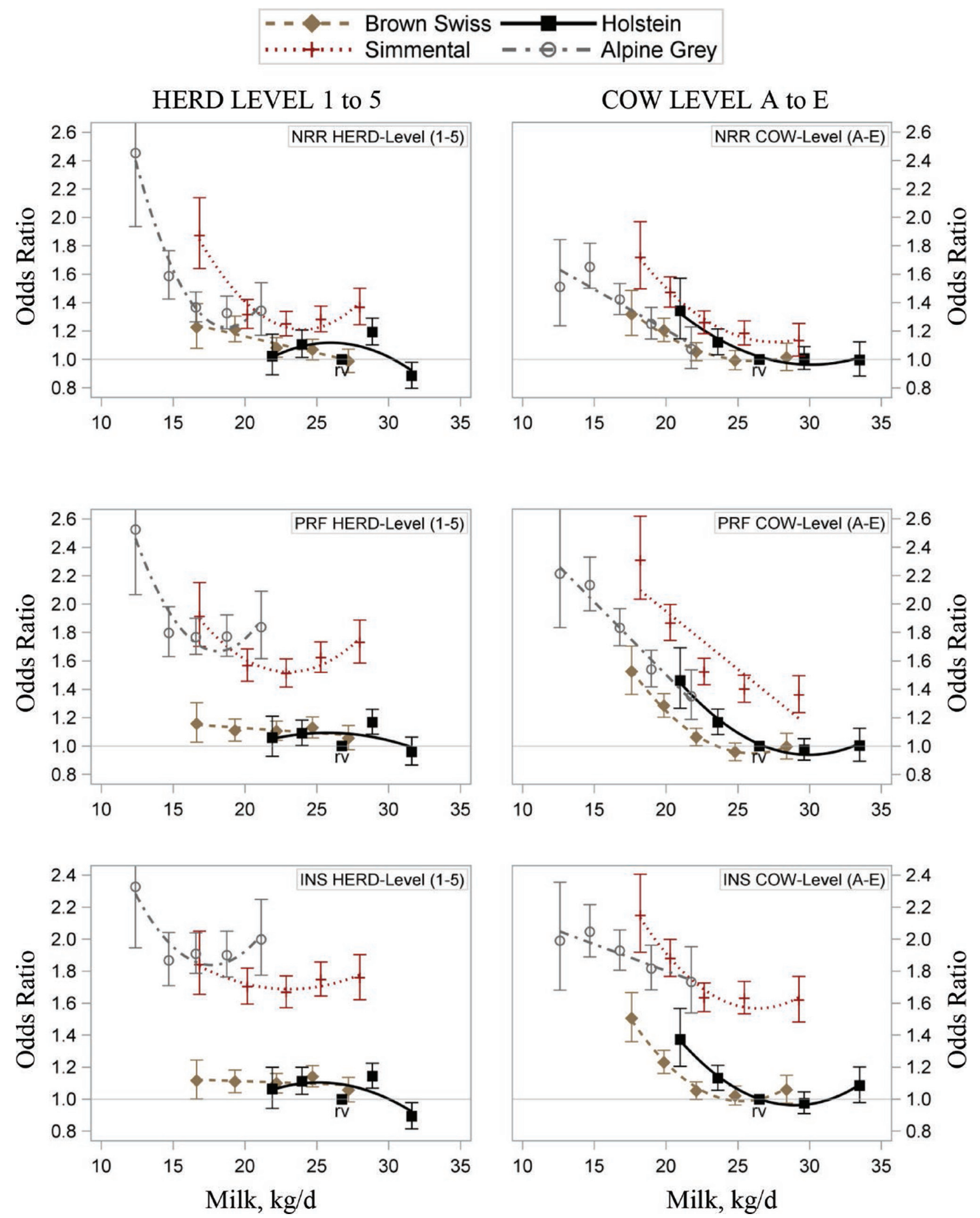

Figure 5. Odds ratio estimates and their confidence intervals for the nonreturn rate after $56 \mathrm{~d}(\mathrm{NRR})$, pregnancy rate at first service (PRF), and number of inseminations to conception (INS) at the herd level and cow-within-herd level. rv = reference value. Color version available online. 
between pregnancy rates and high-producing cows and herds, although the environmental conditions, management systems, and herd sizes differed in the 2 studies.

In the case of the OR for PRF, the main finding is that at Herd-L the dual-purpose breeds are clearly more fertile than the dairy breeds at every production level. The difference between the OR of NRR and PRF in the 2 groups of breeds is explained by the difference between the average NRR and PRF of the breeds. As seen in Table 2, PRF is always lower than NRR: by $17 \%$ in Holstein and Brown Swiss cows, by $12 \%$ in Simmentals, and by $10 \%$ in Alpine Greys. That is, it was more often the case that pregnancy status was not confirmed with subsequent parturition, as predicted by their nonreturn in estrus within $56 \mathrm{~d}$ of insemination, in dairy cows than in dual-purpose cows. This could be attributable to different incidences of estrus detection, abortions, or the culling or selling of cows. With respect to PRF, the dairy breeds did not seem to be much affected by productivity at Herd-L, whereas there was a curvilinear effect with dual-purpose breeds. The negative effect of productivity is evident in all breeds at Cow-L (at least until $25 \mathrm{~kg} / \mathrm{d}$ ), but there is a greater overlap in the breed estimates, and only Simmental tended to be more fertile than the other breeds. Regarding INS, the 2 dual-purpose breeds had a much greater risk of undergoing fewer inseminations per conception than the dairy breeds, and the effect of productivity was lower than other traits, especially for dairy breeds at Herd-L.

\section{CONCLUSIONS}

Our results show that important differences exist among the breeds studied with respect to interval and success fertility traits. It is also clear that reproductive traits are greatly affected by level of milk production and that this is the case for herds with different milk production levels and for cows with different milk yields in similar production environments. The effects of common (herd) and individual (cow) production environments are clearly different from each other and differ according to breed. The dual-purpose breeds (Alpine Grey and Simmental) have a greater reproductive potential than the dairy breeds (Holstein and Brown Swiss), a difference that is only partly attributable to different production levels. These results indicate that there exists a tendency to improve the reproductive intervals and to decrease the success fertility rates from lower production herds to higher production herds, at least up to a milk yield of about $25 \mathrm{~kg} / \mathrm{d}$. Bearing in mind that the survival analysis used in the present study also took into account censored data and their different proportions in different breeds and productiv- ity classes, DO may be considered an overall indicator of fertility. The DO, in fact, depends on the interval to first insemination, success of first insemination, INS, and interval from first insemination to conception. This trait clearly shows that herd productivity has an effect opposite to that of individual productivity. A better production environment could lead to better overall fertility responses, whereas an increase in the milk yield of individual cows within a herd leads to worsening fertility. These associations between fertility and milk production levels are nonlinear at both Herd-L and Cow-L but are more evident moving from low to medium milk yields than moving from medium to high milk yields. Therefore, they affect the dual-purpose breeds more than the dairy breeds, particularly the Holsteins. Within breed, disentangling the effects of milk productivity on fertility at the Herd-L and Cow-L and taking nonlinearity of response into account could contribute to improving the design of population modeling, thus helping in management purposes - for example, fertility in dairy and dual-purpose cattle in precision dairy farming. A better understanding of the fertility rates of different breeds and their different responses to herd and individual productivity levels could provide a useful basis for designing more profitable crossbreeding programs in different dairy systems.

\section{ACKNOWLEDGMENTS}

The authors thank the Associazione Provinciale delle Organizzazioni Zootecniche Altoatesine/Vereinigung der Südtiroler Tierzuchtverbände (Bolzano/Bozen, Italy) for providing the data. This research was financed by the University of Padua (Ricerca Scientifica fondi quota EX 60\%-60A08-421 7943/14). Thanks also to the Mexican National Council for Science and Technology, Ciudad de México, México, for financial support with a $\mathrm{PhD}$ scholarship to the first author.

\section{REFERENCES}

Bello, N. M., J. S. Stevenson, and R. J. Tempelman. 2012. Invited review: Milk production and reproductive performance: Modern interdisciplinary insights into an enduring axiom. J. Dairy Sci. 95:5461-5475. https://doi.org/10.3168/jds.2012-5564.

Cox, D. R. 1972. Regression models and life-tables. J. R. Stat. Soc. B 34:187-220.

Egger-Danner, C., J. B. Cole, J. E. Pryce, N. Gengler, B. Heringstad, A. Bradley, and K. F. Stock. 2015. Invited review: Overview of new traits and phenotyping strategies in dairy cattle with a focus on functional traits. Animal 9:191-207. https://doi.org/10.1017/ S1751731114002614.

Harrison, R. O., S. P. Ford, J. W. Young, A. J. Conley, and A. E. Freeman. 1990. Increased milk production versus reproductive and energy status of high producing dairy cows. J. Dairy Sci. 73:27492758. https://doi.org/10.3168/jds.S0022-0302(90)78960-6.

Heins, B. J., L. B. Hansen, and A. J. Seykora. 2006. Fertility and survival of pure Holsteins versus crossbreds of Holstein with 
Normande, Montbeliarde, and Scandinavian Red. J. Dairy Sci. 89:4944-4951. https://doi.org/10.3168/jds.S0022-0302(06)72545 $-0$.

Huang, C., I. Misztal, S. Tsuruta, and T. J. Lawlor. 2007. Methodology of evaluation for female fertility. Interbull Bull. 37:156-160.

LeBlanc, S. 2010. Assessing the association of the level of milk production with reproductive performance in dairy cattle. J. Reprod. Dev. 56(Suppl.):S1-S7. https://doi.org/10.1262/jrd.1056S01.

López-Gatius, F. 2012. Factors of a noninfectious nature affecting fertility after artificial insemination in lactating dairy cows. A review. Theriogenology 77:1029-1041. https://doi.org/10.1016/j .theriogenology.2011.10.014.

Lucy, M. C. 2001. Reproductive loss in high-producing dairy cattle: Where will it end? J. Dairy Sci. 84:1277-1293. https://doi.org/10 .3168/jds.S0022-0302(01)70158-0.

Malchiodi, F., A. Cecchinato, and G. Bittante. 2014. Fertility traits of purebred Holsteins and 2- and 3-breed crossbred heifers and cows obtained from Swedish Red, Montbéliarde, and Brown Swiss sires. J. Dairy Sci. 97:7916-7926. https://doi.org/10.3168/jds.2014 -8156 .

Nilforooshan, M. A., J. H. Jakobsen, F. W. Fikse, B. Berglund, and H. Jorjani. 2009. International genetic evaluations of fertility traits using multi-trait MACE. Interbull Bull. 39:99-102.

Norman, H. D., J. R. Wright, S. M. Hubbard, R. H. Miller, and J. L. Hutchison. 2009. Reproductive status of Holstein and Jersey cows in the United States. J. Dairy Sci. 92:3517-3528. https://doi.org/ 10.3168/jds.2008-1768.

Phuong, H. N., P. Blavy, O. Martin, P. Schmidely, and N. C. Friggens. 2016. Modelling impacts of performance on the probability of reproducing, and thereby on productive lifespan, allow prediction of lifetime efficiency in dairy cows. Animal 10:106-116. https://doi .org/10.1017/S1751731115001718.

Pryce, J. E., M. D. Royal, P. C. Garnsworthy, and I. L. Mao. 2004. Fertility in the high-producing dairy cow. Livest. Prod. Sci. 86:125-135. https://doi.org/10.1016/S0301-6226(03)00145-3.

SAS Institute. 2012. SAS/STAT Software. Release 9.4. SAS Institute Inc., Cary, NC.

Schneider, M. del P., E. Strandberg, V. Ducrocq, and A. Roth. 2005. Survival analysis applied to genetic evaluation for female fertil- ity in dairy cattle. J. Dairy Sci. 88:2253-2259. https://doi.org/10 .3168/jds.S0022-0302(05)72901-5.

Stocco, G., C. Cipolat-Gotet, T. Bobbo, A. Cecchinato, and G. Bittante. 2017. Breed of cow and herd productivity affect milk composition and modeling of coagulation, curd firming and syneresis. J. Dairy Sci. 100:129-145. https://doi.org/10.3168/jds.2016-11662.

Sturaro, E., E. Marchiori, G. Cocca, M. Penasa, M. Ramanzin, and G. Bittante. 2013. Dairy systems in mountainous areas: Farm animal biodiversity, milk production and destination, and land use. Livest. Sci. 158:157-168. https://doi.org/10.1016/j.livsci.2013.09.011.

Tiezzi, F., C. Maltecca, A. Cecchinato, M. Penasa, and G. Bittante. 2012. Genetic parameters for fertility of dairy heifers and cows at different parities and relationships with production traits in first lactation. J. Dairy Sci. 95:7355-7362. https://doi.org/10.3168/jds .2012-5775.

Tiezzi, F., C. Maltecca, A. Cecchinato, M. Penasa, and G. Bittante. 2013. Thin and fat cows, and the nonlinear genetic relationship between body condition score and fertility. J. Dairy Sci. 96:67306741. https://doi.org/10.3168/jds.2013-6863.

Tiezzi, F., C. Maltecca, M. Penasa, A. Cecchinato, Y. M. Chang, and G. Bittante. 2011. Genetic analysis of fertility in the Italian Brown Swiss population using different models and trait definitions. J. Dairy Sci. 94:6162-6172. https://doi.org/10.3168/jds.2011-4661.

VanRaden, P. M., A. H. Sanders, M. E. Tooker, R. H. Miller, H. D Norman, M. T. Kuhn, and G. R. Wiggans. 2004. Development of a national genetic evaluation for cow fertility. J. Dairy Sci. 87:22852292. https://doi.org/10.3168/jds.S0022-0302(04)70049-1.

Vargas, B., T. Van Der Lende, M. Baaijen, and J. A. Van Arendonk. 1998. Event-time analysis of reproductive traits of dairy heifers. J. Dairy Sci. 81:2881-2889. https://doi.org/10.3168/jds.S0022 -0302(98)75848-5.

Walsh, S. W., E. J. Williams, and A. C. O. Evans. 2011. A review of the causes of poor fertility in high milk producing dairy cows. Anim. Reprod. Sci. 123:127-138. https://doi.org/10.1016/j .anireprosci.2010.12.001.

Weigel, K. A., and K. A. Barlass. 2003. Results of a producer survey regarding crossbreeding on US dairy farms. J. Dairy Sci. 86:41484154. https://doi.org/10.3168/jds.S0022-0302(03)74029-6. 